\title{
Questioning Technology in the Development of a Resilient Higher Education
}

\author{
RICHARD HALL \\ Directorate of Library and Learning Services, \\ De Montfort University, Leicester, United Kingdom \\ JOSS WINN \\ Centre for Educational Research and Development, \\ University of Lincoln, United Kingdom
}

\begin{abstract}
This article considers the impact that peak oil and climate change may have on the future of higher education. In particular, it questions the role of technology in supporting the provision of a higher education which is resilient to a scenario both of energy depletion and the need to adapt to the effects of global warming. One emerging area of interest from this future scenario might be the role of technology in addressing more complex learning futures, and more especially in facilitating individual and social resilience, or the ability to manage and overcome disruption. However, the extent to which higher education practitioners can utilise technology to this end is framed by their approaches to the curriculum, and the sociocultural practices within which they are located. The authors discuss how open education might enable learners to engage with uncertainty through social action within a form of higher education that is more resilient to economic, environmental and energy-related disruptions. It asks whether more open higher education can be (re)claimed by users and communities within specific contexts and curricula, in order to engage with an increasingly uncertain world.
\end{abstract}

\section{Introduction}

The interconnections between education, technology, energy use and carbon emissions have received relatively little attention to date (Joint Information Systems Committee, 2011). In fact, green technology and technological efficiencies are often seen as a fix; a way in which the environmental impact of our high-tech, digitised activities can be offset, in order to enable economic business as usual to continue (New Economics Foundation, 2009). However, there is now an emerging critique of the issue of sustainability tied to the viability of capitalist work within the context of reduced liquid fuels availability, and a lack of control over carbon emissions (Pielke, 2010; Greer, 2011). Consideration of these implications is a reminder that higher education (HE) does not operate in a vacuum (Thrift, 2010).

This, in turn, has implications for education and the implementation of educational technology within capitalism. By March 2011, the price of crude oil stabilised above US\$100 per barrel after reaching a short-term peak of US\$118 per barrel (US Energy Information Administration, 2011). Practitioners in HE might ask why this matters to them and their work, given that the price of oil has fluctuated, historically tied to a range of immediate geopolitical and economic factors (Kilian, 2009). Why is this time any different? This article relates current analyses of global disruptions to the role of technology in HE, in order to describe a possible future scenario for higher learning. The first part of this article sets out to analyse this question by drawing on recent research which, it is argued, should compel those working in HE to think much more seriously about a future of research, teaching and learning that is substantially impacted by the 
socio-economic effects of environmental volatility. The article then reflects on a recent editorial published in the British Medical Journal (Raffle, 2010), where health professionals in the United Kingdom undertook a scenario-planning exercise around the likely impacts of peak oil on the provision of public health services, in order to reflect on the place of educational technology in HE. Finally, the article suggests ways in which the uses of technology in HE might facilitate a new form of resilient education based on open educational practices.

\section{Thinking the Unthinkable: peak oil and climate change}

\section{Peak Oil and Energy Costs}

Peak oil is the point at which the maximum rate of oil production is reached. Following this peak, oil production declines due to exponentially falling supply. Peak oil does not refer to the point at which there is no more oil left in the earth, but rather acknowledges that the production of oil and the net energy it provides measurably decreases over a number of years and it becomes increasingly uneconomical to produce and consume. Hubbert's (1956) peak oil theory has been empirically observed on a national level in 54 of the 65 largest oil-producing countries (Aleklett, 2005). For example, the United Kingdom experienced peak oil in 2000 (Zittel, 2001) and the USA experienced the peak of production from its national oil fields in 1970 (Gail the Actuary, 2009). Worldwide, the discovery of oil measured by volume peaked in 1964 (Gail the Actuary, 2009) and the rate of current oil discovery, and therefore global oil reserves, is inadequate to meet projected demand (Gail the Actuary, 2010; Owen et al, 2010). Since May 2005, the production of all liquid fuels from current fields has reached a plateau, with very little additional volume being produced. At the same time, the price of oil has doubled (Ace, 2009). Despite these observations, the theory of global peak oil was contested until the International Energy Agency (IEA, 2010a) clearly stated that the production of 'conventional oil' peaked in 2006 and, since then, any additional demand for oil has been met by so-called 'unconventional oil' (i.e. tar sands, deep water reserves and biofuels). Unconventional sources of oil are much more energy-intensive to exploit and therefore produce less net energy than conventional crude oil, and their production is likewise more expensive. Therefore, as conventional sources decline at more than $4 \%$ per year, the replacement nonconventional oil pushes prices upwards if demand is to be met.

The significance of global oil production for the provision of HE is socio-economic, in that global gross domestic product (GDP) closely correlates to global oil production. In other words, the production of wealth depends on the production of energy, and the world consumes more energy from oil than any other single source (International Energy Agency, 2010a, 2011). Although the majority of oil worldwide is used to make petroleum for transportation and, in some countries, space heating and electricity, it is essential to many other sectors of the world economy, including the production of food (Aleklett, 2010), plastics and pharmaceuticals. In this, HE is implicated through its strategies for growth, like internationalisation and the constant renewal of technologies. In the United Kingdom, oil accounts for $39 \%$ of the total primary energy demand and petroleum accounts for $45 \%$ of the total energy consumption. Although oil accounts for just over $1 \%$ of the United Kingdom's production of electricity (Department of Energy and Climate Change, 2010), to a greater extent it underwrites the production and distribution of other fuels because of its versatility and the overwhelming reliance on oil for transportation. It is therefore not surprising that the price of other forms of energy, such as electricity and gas, is affected by the price of oil (Oil Depletion Analysis Centre \& Post Carbon Institute, 2010), with huge implications for universities as HE budgets are cut (Shepherd, 2010).

The importance of oil to economic growth will become an increasing concern to universities, which are themselves seen as engines of growth (Corbett Broad, 2010; Mohrman, 2011; Willetts, 2011). Hirsch (2008) has calculated that a decline in the global production of liquid fuels (i.e. unconventional and conventional oil) would lead to approximately a 1:1 ratio in the decline of global GDP. In the same article, the post-peak decline in oil production is calculated to be between $2 \%$ and $5 \%$ per year, suggesting a similar decline in GDP. By comparison, the decline in GDP during the global recession from 2008 to 2009 was 5\% (World Bank, 2011). In the United Kingdom, the Industry Taskforce on Peak Oil and Energy Security (ITPOES, 2010) has likened the effect of an imminent 'oil crunch', due mid-decade, to the current credit crunch. Their report also shows the 
'highly suggestive' correlation between oil price spikes and US recessions, stating that every US recession since 1960 has been preceded by rapid oil price rises, and that when the price of oil exceeds $4 \%$ of US GNP, a recession occurs shortly afterwards. In March 2011, this equated to an oil price of around US\$80 per barrel, and therefore April 2011's price for dated Brent spot crude oil of US\$118 per barrel is a threat to economic growth in oil-importing countries. Moreover, within capitalism, a threat to economic growth is a threat to social stability, as is noted whenever there is a recession or conflict (Colgan, 2011), with clear implications for the role of HE (Thrift, 2010).

These issues were amplified by the US Department of Energy's 'Hirsch report', which stated:

The peaking of world oil production presents the U.S. and the world with an unprecedented risk management problem. As peaking is approached, liquid fuel prices and price volatility will increase dramatically, and, without timely mitigation, the economic, social, and political costs will be unprecedented. (Hirsch et al, 2005, p. 4)

The difficulty of moving away from the use of oil is highlighted by the Hirsch report, which states that 'a minimum of a decade of intense, expensive effort' is required to migrate from our current use (Hirsch et al, 2005, p. 5). Businesses have strategically targeted waste in energy usage of technology, and attempted to profit from its measurement and monitoring as part of a strategy to roll out smart technologies (IBM, 2010), which themselves are highly contentious (Levitt \& Glendinning, 2011). Relatively little has been done to address this anticipated problem within HE due to its focus on business as usual (Higher Education Funding Council for England, 2010). Within the current model, business as usual extends the global demand for oil by at least $15 \%$ over the next 25 years (International Energy Agency, 2010b).

\section{The Rebound Effect, Carbon Emissions and Technological Efficiency}

One of the measures designed to improve the security of energy supplies in the face of declining liquid fuel availability is to improve energy efficiency through technology. This effectively allows actors to do the same (or more) work using less energy than before. This continual drive for energy efficiency is also closely related to societal carbon reduction targets, again promised through technology. The European Union directive on climate change sees efficiencies as 'one of the key ways in which CO2 emission savings can be realised' (European Commission, 2008, p. 8).

However, there is a problem when claiming absolute targets for energy efficiency, which is known as the 'rebound effect' (Sorrell, 2007; Breakthrough Institute, 2011). Thus, while institutions like universities might save energy through efficiencies like powering down personal computers (PCs) in laboratories, they spend part of those savings on other activities that use up energy. For instance, university procurement procedures enable the replacement of PCs with more energyefficient models, only to embed those savings in the production and use of more technologies, which themselves increase the demand for energy and produce emissions. The Open University in the United Kingdom studied energy-efficiency measures, comparing the energy consumption of distance learning courses to campus-based courses, and concluded that the former did not result in an overall reduction of energy usage, due to rebound effects. Although less energy was used on campus, the use of energy was transferred to people's homes and purchasing habits. In practice, it was argued that: 'Service system efficiency in itself is not a panacea for sustainable consumption as the gains are easily offset by rebound effects together with an increase in the number and variety of products consumed' (Herring \& Roy, 2002, p. 538).

Allied to an analysis of rebound effects is the discourse around economic growth and technological progress. The conclusions of the UK Energy Research Centre report on energy consumption, emissions and promoting technological efficiencies have implications for $\mathrm{HE}$ practitioners:

In developed countries, energy use as conventionally measured has grown more slowly than the economy as a whole. From this, it is generally concluded that technical change has improved the efficiency with which energy is used and thereby helped to 'decouple' energy consumption from economic growth. However, once different energy sources are weighted by their relative 'quality' or economic productivity, the coupling between energy consumption and economic growth appears far stronger. Taken together, the evidence reviewed in this report suggests that: 
a) the scope for substituting other inputs for energy is relatively limited; b) much technical change has historically increased energy intensity; c) energy may play a more important role in economic growth than is conventionally assumed; and d) economy-wide rebound effects may be larger than is conventionally assumed. (Sorrell, 2007, p. vii)

This has led Jackson $(2009$, p. 8) to argue that while there is clear evidence of a relative decoupling in the use of fossil fuel energy and economic growth, any improvements in energy (and carbon) intensity ... were offset by increases in the scale of economic activity over the same period'.

The difficulty of decoupling energy consumption and economic growth is understood in terms of the impact of human activities $(\mathrm{I})$, which is determined by the overall population $(\mathrm{P})$, the level of affluence $(\mathrm{A})$ and the efficiency of technology $(\mathrm{T})$, given as $\mathrm{I}=\mathrm{P}$.A.T. In spite of hopes that technological efficiency will drive down the impact of consumption, it is only an efficiency factor in the equation, whilst population and affluence are scaling factors. As a result, Jackson states that:

the overall result depends on improving technological efficiency fast enough to outrun the scale effects of affluence and population ... we now appear to be in a self-reinforcing positive feedback between affluence and technology, potentially - and I emphasise potentially - geared in the direction of rising impact. (Jackson, 2007, p. 6)

This view of the conflicted nature of energy use, carbon emissions and economic growth led Pielke (2009) to note that technological efficiency, although vitally important, does not, as we might expect, lead to an overall reduction in emissions or energy consumption. Pielke investigated the impact of the United Kingdom's economic activities in the context of its 2008 Climate Change Act, and the target for an $80 \%$ reduction in carbon emissions by 2050 , by projecting from historical data for population, decarbonisation and growth in GDP. At best, technological change, including changes in education towards services and away from energy-intensive production activities, only balanced emissions from the overall growth of the economy. The logic of these relationships means that 'carbon accumulating in the atmosphere can be reduced only by reducing (a) population, (b) per capita GDP, or (c) carbon intensity of the economy' (Pielke, 2009, p. 2). Understandably, academics working in this space see technological innovation as the only realistic policy choice (Royal Academy of Engineering, 2010), although it has also led to emissions and energy use being outsourced to industrialising countries. As a result, any balance is lost in favour of rising energy use and emissions (Helm, 2007).

This projected outcome has major implications for the socio-economic roles of universities, especially given that any transition from established to new technologies is normally in the region of 30-40 years (Royal Academy of Engineering, 2010). Both the transition to the use of new technologies and the building of any new infrastructure are major challenges. This task is not just technological or economic, but is also political and social. It is perhaps in this space that HE has a major role to play through its networks and communities, as the infrastructural and cultural changes demanded require major systemic changes to millions of individual actors and assets. Major training and development programmes will be required, and engagement will require disciplinary and technological agility because 'the changes to the UK energy system required to meet any of the scenarios will be considerable and disruptive' (Royal Academy of Engineering, 2010 , p. 14). These requirements stand against the current motive forces within and across HE for economic growth and business as usual: namely, the implementation of more technology; outsourcing linked to green information and communication technology agendas; further internationalisation and extension of competitive markets; and distance and work-based learning. In light of this, the impact of $\mathrm{HE}$ on carbon emissions and energy use, in the context of economic growth, needs critique.

What seems clear, then, from expert analyses is that technology as a solution is being overstated, in order to avoid the greater social, environmental and economic effects of an aspirational and growing population. The hopes for efficient technology emerge as an apparently politically neutral solution (Jackson, 2007), and yet the history of the production and use of technology implies that this is hugely problematic within capitalist societies that pursue economic growth through strategies for commodification, profit maximisation and accumulation (MeiksinsWood, 1997; Noble, 1998; Harvey, 2010; Greer, 2011). Jackson succinctly nails the problem faced by society in general, and HE in particular: 
In short, society is faced with a profound dilemma. To resist growth is to risk economic and social collapse. To pursue it is to endanger the ecosystems on which we depend for long-term survival. For the most part, this dilemma goes unrecognised in mainstream policy or in public debate. When reality begins to impinge on the collective consciousness, the best suggestion to hand is that we can somehow 'decouple' growth from its material impacts. Never mind that decoupling isn't happening. Never mind that no such economy has ever existed. Never mind that all our institutions and incentive structures continually point in the opposite direction. The dilemma, once recognised, looms so dangerously over our future that we are desperate to believe in miracles. Technology will save us. Capitalism is good at technology. So let's just keep the show on the road and hope for the best. (Jackson, 2009, p. 102)

In the face of these issues, practitioners concerned about progressive and technologically enhanced forms of HE might usefully reflect on the form and content of our institutions.

\section{Developing Resilience: comparing the education and health sectors}

In a British Medical Journal editorial, Raffle offered a brief assessment of peak oil and its likely effects on the form and nature of health and health care, noting that:

oil is a primary raw material for many drugs, equipment, and supplies; that transport for patients, staff, deliveries, and services is heavily oil dependent; that currently suppliers are not required to provide business continuity plans around fuel supply shortages; and that rising oil costs would seriously affect health service budgets. (Raffle, 2010)

The editorial acknowledges a range of challenges tied to oil dependency and lists the outcomes from a series of workshops where peak oil and health care was discussed. Participants described the positive features of 'a society that has successfully reduced its reliance on fossil fuels', including the following:

- All essential drugs are now produced without petrochemicals, some locally.

- All National Health Service (NHS) estate is a net energy generator.

- Every NHS facility is accessible on foot, by bicycle and by public transport.

- Digital infrastructure is used for high-priority communication, including that between patients and health services.

- Landline telephone and radio are important.

- The most essential and best-value aspects of modern health care have been preserved; those of only marginal benefit have been abandoned.

- Towns and cities have high-density housing - more lodgers, more boarding houses and more shared housing.

- All land and space that can be is used for food production. Many more people are employed in food growing and preparation, and people's involvement with food is far greater.

- Everyone does some form of volunteering work for their local community.

- Legal structures are different; limited liability is gone; drivers of growth are gone; and the ability of an individual to pursue expensive legal challenges is gone.

- The norm is for systems designed for the prosperity of the community and the preservation of non-renewable resources.

- Health care is rationed and some conditions cannot be treated.

Whilst some features may appear idealistic, these workshops focused on the attributes of a successful transition away from oil towards a radically different world where carbon emissions must be reduced by $80 \%$ by 2050 . This health-care scenario does not necessarily describe a futuristic, high-tech world, but rather one of low energy use with appropriate technology that is powered in large part by the microgeneration of electricity. People live closer together, walk more and grow their own food. Digital infrastructure is reserved for critical uses and people take more responsibility for themselves, rather than outsourcing the management of their needs. Notably, this scenario points towards a zero-growth economy, where resources and services are rationed (New Economics Foundation, 2009).

Given that universities in the United Kingdom currently contribute $2.3 \%$ of GDP (Department for Business, Innovation and Skills, 2009), how a university might operate under a 
stable but zero-growth economy is important, and is connected to issues of prosperity. Jackson (2009, p. 43) has argued both that basic entitlements like education need not intrinsically be coupled with growth and that growth itself is unsustainable: 'Some countries achieve remarkable levels of flourishing with only a fraction of the income available to richer nations.' This is central to a critique of possible future scenarios because growth based on resource consumption and rising environmental despoliation is unsustainable and, under present conditions, de-growth is unstable as it diminishes consumer demand, leading to increasing unemployment, falling competitiveness and a spiral of recession. This dilemma 'cannot be avoided and has to be taken seriously. The failure to do so is the single biggest threat to sustainability that we face' (Jackson, 2009, p. 8).

Education practitioners might usefully reflect on the role of the HE sector and the university in developing and delivering pedagogies and curricula that encourage radical changes in a future where there may be less abundance and freedom of choice than previously experienced, and a recalibrated view of progress and growth. This includes making decisions about the scale and scope of technology implementation and pervasiveness. Given capitalism's current provision of hightech, industrialised education, the actions that universities might take to remain relevant are critical. This does not imply that participation in HE will automatically diminish or that HE will become more niche or privileged, or that technology use will be reduced, especially as there is evidence that on-site HE energy consumption is not tightly coupled with student numbers (Ward et al, 2008). In fact, there may be a role for universities in acting as technological hubs for communities and networks. A useful case study here is Cuba, which has roughly the same level of educational participation as the United Kingdom, yet with a GDP per capita that is just a quarter of that of the United Kingdom (United Nations, 2010). Cuba's energy use per capita is also just a quarter of the United Kingdom's consumption (World Bank, 2010), suggesting that while GDP and energy consumption are closely coupled, GDP and educational participation need not be. These issues are important in imagining possible futures and roles for technology in HE, and in the contribution of the university to reimagining resilient social relationships.

Resilience is central to a reimagining of possible futures. It denotes the ability of individuals and communities to learn and adapt, to mitigate risks, to prepare solutions to problems, to respond to risks that are realised, and to recover from dislocations (Hopkins, 2009). For Hopkins (2009), resilience is 'the capacity of a system to absorb disturbance and reorganise while undergoing change, so as to retain essentially the same function, structure, identity and feedbacks'. This focuses upon defining problems and framing solutions contextually around our abilities to change and adapt rather than control and manage, in ways that are shared, reciprocal and self-reliant. Resilience is fundamental to sustainability, in enabling individuals and communities to manage crises and disruptions, and to find alternatives.

Edwards (2009) has argued that formal and informal education play a major role in engaging people with resilient responses to disruptions. He also highlighted the need for society to become increasingly focused on resilience, in order to adapt to disruptions like the impact of energy shortages. In this, universities need to consider the use and benefits of technology, both in terms of business continuity and as tools for teaching about resilience. For example, is the promotion of cloud computing and ubiquitous Internet access increasing our resilience or not? Does a focus on locative, pervasive mobile computing, and any time, anywhere access to online information and communication, enhance community resilience? How might an engagement with the open web and hacker communities, rather than corporate information technology (IT) systems, enhance shared problem solving? What is the role of digital literacy and research into digital divides in developing resilient responses to crises, at the levels of the individual, the network, the community and the institution?

The three core characteristics of resilience (Hopkins, 2009) help to extend an analysis of the role of educational technology within this context. Firstly, resilience is communal and comes through diversity within networks or associations, and encompasses a broad base of livelihoods, skills and capabilities, resource use, and access to human and energy systems. These skills are shared and transdisciplinary. Secondly, modularity within communities or networks underpins increased self-reliance. Thus, the ability of communities to tap into 'surge protectors', such as diverse areas of expertise or resource supply, can help them to achieve their aims. These communities are networked and decentralised. Thirdly, tightness of feedback loops, so that people are not divorced or outsourced from the outcomes of their decision making and actions, ensures 
enhanced planning and delivery of services. As technology offers reach, usability, accessibility and timely feedback, it is a key to developing a resilient HE, with openness at its core.

\section{Technology, Resilience and the Potential of Open Education}

The place of technology in pedagogic discourse is a core element of HE research and development (Ravenscroft, 2009; Facer \& Sandford, 2010; Higher Education Academy \& Joint Information Systems Committee, 2010; Selwyn, 2010). Emergent work focuses upon personalisation, informal learning, open education and, latterly, building resilience (Hall, 2009; Attwell, 2010; Downes, 2010; Winn, 2010). It has been contended that the ability of users to integrate a range of institutional and non-institutional networks, content and tools extends their reflexivity and identity as students and citizens (Hall \& Hall, 2010; University of Reading, 2010).

However, there is a danger that an uncritically deterministic approach emerges, with a view of students as expert consumers of technology (Department for Business, Innovation and Skills, 2009; Higher Education Funding Council for England, 2010). There is a tendency for the 'how' of technological implementation to be elevated ahead of the 'why' of its use, and for the sociohistorical structures and imperatives imposed by the dominant political economy to be ignored (Gartner, 2010; Johnson et al, 2011). These technical imperatives underpin a strategy of business as usual, doing more for less, cost-effectiveness and increased productivity of labour, and they include, but are not limited to, the following:

- Closed, enterprise-level and private cloud computing systems architectures, focused on thirdparty technologies rather than locally sourced and maintained networks and solutions.

- Outsourcing services like data storage and management, often to cloud-based providers, based on perceived economic efficiencies ahead of a critical analysis of environmental impact.

- Enclosure and commodification of content and communication provision within app-based and app-augmented reality services, e-books and the location-based, real-world web.

- Persistent and ongoing procurement and renewal of hardware and software, both institutionally and personally, irrespective of the environmental sustainability over a machine's life course.

- A focus on personalised and private use of technologies as a form of identity commodification, even within notionally shared services, for data management and curriculum delivery.

- Always on, any time, anywhere access to services, based upon latency, resilience and failover. In terms of mobile phones, this includes a move towards a 4G standard, with sensory networks and context-sensitive, content delivery architectures, which 'will play a key role in expanding the impact of IT in the physical world' (Gartner, 2010).

- Increased and more pervasive computing power at lower economic cost, including the ability for just-in-time processing of more dynamic, multimedia services and content, and the use of media tablets and kinaesthetic or gesture-based interfaces.

- Increased prioritisation of digital technologies in strategies for internationalisation, work-based learning and distance education. This includes a drive for learning analytics, linked data and data-driven decision making, possibly folding in work on the Semantic Web (Gartner, 2010). The point is to commodify further social relationships and our lived experiences: 'the value resides in applying them in new applications such as social analytics and sentiment analysis' (Gartner, 2010).

Arguably, these strategies for the implementation of educational technology are being used as politically neutral mechanisms for managing the scarcity of resources like money and energy, or the overproduction of carbon, across HE (Gartner, 2010; Higher Education Funding Council for England, 2011). They are not geared to defining strategies for adapting to socio-environmental disruption, and they do not enable universities or their networks to engage with issues of diversity of provision, modularity and feedback. In part this is because the integration of digital technology into the fabric of society and social discourse conceals and distances the complexity and destructiveness of its modes of production, procurement, distribution and consumption from its consumers (Hall, 2010). In Noble's (1998) terms, this is the 'disarming disguise' of high technology, which abstracts our human condition from our sociocultural environment. In order to make sense of a future scenario of wider societal disruption, in the form of large-scale public sector debt and budgetary cuts, climate change, energy security and peak oil, educational technology must be seen 
as socially, culturally and politically grounded for resilience (Feenberg, 1999; Hemmi et al, 2009; Payton \& Williamson, 2009; Selwyn, 2010).

These social issues demand communal responses. In terms of HE, this demands a discourse of educational technology that is more open in nature and implementation, and less universal or totalising in the outcomes it prescribes, in terms of which specific technologies to deploy or how they should be institutionalised. By focusing on resilient responses to disruption, a more radical critique of educational technology beyond models of business as usual emerges. For Facer \& Sandford (2010, p. 75), this involves questioning the chronological imperialism of accounts of inevitable and universal futures', focused upon always-on technology and its allegedly participative, inclusive, democratic possibilities. Neary \& Winn (2009) have amplified this demand for reformation to describe more revolutionary possibilities embedded within the social relations of education, and which might be challenged though more open use of technologies. They stress the significance of the student actively producing her lived experience, with the production of intellectuality being a critical, pedagogic act of resistance, in opposition to the mere consumption of knowledge (Giroux, 2008). The student is encouraged to transcend and live in excess of her socially defined role as a learner. This critique includes a fuller engagement with the possibilities of open, shared education, managed in open, shared technologies, to build resilient responses to moments of crisis (Jones et al, 2010).

This is not to argue for the institutionalisation of open education - for instance, in its reduction into the form of open educational resources (OERs) - as a strategy for overcoming disruption and developing resilience. These forms appear to be innovatory, only to be a rehashing and reinforcement of many of the defining attributes of mass production: automation and standardisation, efficiency and the reification of the resource as product or commodity. For instance, in their institutionalised form, OERs refer to the free movement and regeneration of reified commodities protected by liberal property laws (Creative Commons) that guarantee a level of autonomy to digital objects over and above the rights of teaching (labour) and learning (apprenticeship), from which they are abstracted. They risk the promotion of pedagogy-asproduction, curriculum-as-distribution and learning-as-consumption, with institutional repositories acting as marketplaces for selling institutionalised goods. In parallel, the labour that produces OERs is placed under the control and supervision of quality assurance, through impact measures. In the institutionalisation of openness, technology risks becoming the cause of our educational provision rather than being a variable of its production (Noble, 1984) or a variable of our engagement with disruption.

Thus, in adapting to disruption, educational technology might underpin truly open, socially driven spaces, where the student learns to become a revolutionary social being rather than an institutionalised agent (Neary \& Hagyard, 2010). This open approach breeds mass, social intellectuality (Neary \& Winn, 2009), which is geared to communal problem solving and transformation. Open technology is critical in this transformatory, educational work, for it connects social beings within and beyond the institution. This connectivity is a critique of closed, institutionalised systems of education, which are reinforced through locked institutional technologies. An engagement with open education enables us to examine our 'power to' change our social relations, rather than to exist in a state where someone or something has 'power over', or encloses, both our work and ourselves (Holloway, 2002). The possibilities for developing resilience that emerge from the implementation of more open educational technologies include:

- enhancing our ability to create shared spaces for reflecting upon our participation in the activity and labour of (self-)discovery and (self-)invention (Attwell, 2010);

- catalysing a culture and set of values that offer spaces for cultural reinvention;

- organising and engaging with communal rather than libertarian responses to crises where we are deeply connected to the impact of our activity; and

- transforming democratic and participative social relationships.

Situating educational technology within a truly open education is a starting point for developing a resilient education, which rejects a closed, essentialist discourse of efficiency, value for money and more for less (Department for Business, Innovation and Skills, 2009; Willetts, 2011). In the face of disruption, models for a resilient education, underpinned by open approaches to educational technology, are critical. 


\section{A Resilient Education?}

How can educational technologies underpin a resilient education in the face of peak oil and climate change? If resilience is a function of diversity, modularity and feedback, can we model some possible uses of educational technologies which might themselves be open-sourced for others to use? Central to any such modelling is the curriculum, situated and designed socially, with a focus on its shared production and governance, in a very public and practical way (Williams, 1961). Such relationship-based curricula will utilise technologies that enable students to work collaboratively to reassert the idea of the university as a site for critical action in society (Peer to Peer University, 2010; Really Open University, 2011).

This, then, makes the use of educational technologies part of a wider educational project that looks at what the university is for and the nature of its associations. One risk is that by focusing on what are termed the 'low-hanging fruit' of energy efficiency, like replacing desktop PCs with more energy-efficient laptops or deploying multifunctional devices (IBM, 2010), the fundamental disruptions of peak oil and climate change are ignored in favour of discussing ill-defined changes. Thus, IBM (2010) claims that: 'Ultimately, the biggest potential game changer lies in modifying the operational and functional architecture that underpins all the business's systems.' In order to maintain business as usual, to increase affluence and not to impact population growth, societies are asked to consider technological efficiency. The same difficulty exists in redefining how the incorporation of educational technology might be made more resilient within capitalism, beyond uncritical developments like outsourcing and shared services, in particular where hype-cycles predicate growth on technological progress.

However, focusing on the technical imperatives given above, coupled to the three criteria for resilience and the outcomes of the health-care peak oil scenarios, might indicate some possibilities for further work towards a resilient education utilising technology in a more meaningful way. The outcomes of the health-care scenario-planning focused on: doing, producing and consuming differently in a more diverse set of community ecologies; doing more networking and community engagement locally, and between distributed, modular communities; rationing the always-on access to resources for the whole community; and essential, planned and shared work that maintains the existence of the community through feedback on actions and activities.

As with health care, possibilities for education and educational technology cannot be divorced from global solutions. However, for universities, possibilities might include the following:

- Open systems architectures are implemented, focusing upon open-sourced, communitydesigned and community-implemented technologies in an appropriate mix with cloud-based solutions. Educational technology is a public rather than a private or institutionalised good.

- Increased prioritisation of digital technologies in strategies for associational democracy, modular community-building, and the diversity of skills sharing and development. Community- and problem-based curricula focus upon developing social relationships and lived experiences, so that communities get immediate feedback on the impact of their actions and solutions.

- University networks act as hubs for local community-level engagement with technologies and high-level digital processes. Technologies are used for maintaining the diversity of skill sets within and across communities, rather than commodifying them or chasing the latest hype.

- Digital identities are forged socially, rather than being privatised, and individual access to the Web is less of a right than community access, in order to maintain the modularity of skills. A literacy of openness, which legitimises sharing as social practice and as social process, is central.

- Technological deployment depends on local net energy generation, with essential, high-powerinput tasks requiring timetabling and negotiation. Community consensus-building is used to plan upgrades, redundancy, latency, etc., and always-on, any time, anywhere access to services becomes less important.

- Outsourcing decisions are based on community need related to a critical analysis of environmental impact, rather than on a discourse of cost-effectiveness, monetisation, economic value and efficiency. There is a lessening of an expectation of always-on access to data, information and services.

- The relevance of marginal developments like app-based, locative and augmented reality services in our current moment is questioned through consensus. 
- Persistent and ongoing procurement and renewal of hardware and software is rejected in favour of reuse and repurposing. There is an acceptance of less energy-intensive, individualised access to processing power.

- The use of technology in open education rejects a post-colonial discourse focused upon new markets for one of modularity and sharing expertise.

- Students and staff produce and share their open curricula and artefacts, through transdisciplinary approaches to global crises like peak oil and climate change. Solutions are not a new form of currency, but help maintain the diversity of expertise in a community and help connect modular networks together. Issues to do with copyright, data protection and intellectual property are less important than sharing.

The focus here is on open and social, rather than individual access to technology as the driver for ensuring communal resilience. This moves away from constant innovation in technology and technological practices for hype's sake, in order to empower ever more diverse groups of learners. This is not about relocalisation, as these are global issues. The aim is for open technological solutions to help recast new modes of production, nested in community-based curricula and where institutions are hubs rather than having new power over products and labour. Online engagement is one form of socially emergent and negotiated practice that is managed in public, and then dissolved into the fabric of community. However, moving beyond these risks, in order to develop an open curriculum for resilience, is more complex than a technological fix, and requires us to recognise and engage in the critique of an assemblage of socio-environmental activities or practices related to the production, exchange and consumption of life (Harvey, 2010). Situating educational technology with an open curriculum for resilience enables ways of challenging hegemonic, mental conceptions of the world and framing new social relations in light of developing crises.

\section{Conclusion}

In a future of peak oil, climate change, energy depletion and low or no economic growth, the current forms of HE look increasingly unsustainable. How might universities engage their communities in a project of adaptation to new socio-economic and environmental realities? Based on an analysis of business-as-usual and health-care scenarios, one possible model is a more community-based, educational lifestyle, which will be hugely challenging to implement and take several generations.

Open forms of higher learning and HE must be central to a shared engagement with socioeconomic disruption, and in framing spaces for personal and communal resilience. A key role for open curriculum development is the critique of hegemonic discourses and the contexts in which they emerge, so that they can be challenged and so that co-governance as well as co-production is enabled and tested. A key role for technology, in a world of increasing uncertainty and disruption, is to provide spaces for individuals to engage in authentic partnerships, in mentoring and enquiry, and in the processes of community, social governance and action.

There is still a risk that the provision of frameworks for free associations between individuals will leave some people marginalised, and the creation of appropriate contexts that spark or forge opportunities for participation is pedagogically critical. Hence, a literacy of openness is required, in order to overcome tensions over the ownership of technology, the role of networks and practices, social engagement with communities at scale, and the validation/accreditation of activities. Despite these tensions, the capacity of technology to improve the opportunities for people to work together to shape and solve problems, and to further their critical understanding of themselves and of the world they live in, is significant. Thus, the appropriate use of technology underpins the development of an open curriculum for resilience in three areas:

1. The enhancement of student agency in producing both relationships within and across open communities and open, socially situated tasks is important. The student's power over the tools she uses and her power to negotiate agreed sociocultural norms is fundamental here, although issues to do with social anxiety, difference, self-conception and allegiance within closed groups, and the marginalisation of certain users, form potential risks. However, a modular approach to the use of technology for agreed tasks in meaningful networks is one aspect of defining resilience. 
2. Reframing HE experiences as open, in order to allow learners to test their self-concept in communities, is critical. Educational technologies offer an array of supportive networking contexts where learners can model practice and self-expression. Formative development is ongoing and demands a range of open engagements on a range of tasks with a range of roles in a range of networks. This diverse learning approach is a second aspect of defining resilience.

3. Feedback for learning from multiple perspectives underpins authentic personal development. Technologies facilitate near real-time feedback and enable the student to recognise the impact of her actions, which is a third aspect in the definition of resilience.

In this tripartite approach, the production and reuse of artefacts is of secondary importance to the social relationships that are redefined by educators and students, and the focus on people and values that is in turn assembled through open education (Lamb, 2010). In overcoming alienation and disruption, a resilient education underpinned by open technologies and architectures enables us to critique and overcome unsustainable, commodified, institutionalised forms of education. The challenge is to develop such a critique in the face of everything.

\section{References}

Ace (2009) World Oil Production Forecast - Update November 2009, Oil Drum, 23 November. http:/ / bit.ly/8pQlo0

Aleklett, K. (2005) The Oil Supply Tsunami Alert. http:/ / bit.ly/ejNSyH

Aleklett, K. (2010) Agriculture as Provider of Both Food and Fuel, Aleklett's Energy Mix, 19 May. http: / / bit.ly/h4GRw1

Attwell, G. (2010) Notes on Open Education and Critical Pedagogy, Pontydysgu - Bridge to Learning, 2 August. http:/ / bit.ly/d3a2kK

Breakthrough Institute (2011) 'Energy Emergence: rebound and backfire as emergent phenomena' - report overview, 17 February. http:/ / bit.ly/grWv15

Colgan, J.D. (2011) Oil, Revolution, and International Conflict: the origins of resource-backed aggression. http: / / bit.ly/f9YgsH

Corbett Broad, M. (2010) Higher Education's New Competitive Landscape, Leader to Leader, 59, 14-17.

Department for Business, Innovation and Skills (BIS) (2009) Higher Ambitions: the future of universities in a knowledge economy. London: BIS. http: / / bit.ly/9IidAg

Department of Energy and Climate Change (DECC) (2010) Digest of United Kingdom Energy Statistics (DUKES). London: United Kingdom Statistics Authority. http:/ / bit.ly/biq7Yk

Downes, S. (2010) Collaboration and Cooperation, 12 April. http:// bit.ly/hvm9zm

Edwards, C. (2009) Resilient Nation. London: Demos.

European Commission (2008) 2020 by 2020: Europe's climate change opportunity. Communication from the Commission to the European Parliament, the Council, the European Economic and Social Committee and the Committee of the Regions, $\operatorname{COM(2008)} 30$ final, Brussels, 23 January. http://bit.ly/g7w653

Facer, K. \& Sandford, R. (2010) The Next 25 Years? Future Scenarios and Future Directions for Education and Technology, Journal of Computer Assisted Learning, 26(1), 74-93. http: / / dx.doi.org/10.1111/j.1365-2729.2009.00337.x

Feenberg, A. (1999) Questioning Technology. London: Routledge.

Gail the Actuary (2009) Oil Production Is Reaching Its Limit: the basics of what this means, Oil Drum, 16 November. http:/ / bit.ly/U3bfz

Gail the Actuary (2010) Science 1101 Part 1: the science of oil and peak oil revisited, Oil Drum, 20 June. http: / / bit.ly/aabvUq

Gartner (2010) Hype Cycles 2010. http:/ / bit.ly/aQFgs0

Giroux, H.A. (2008) Border Crossings: cultural workers and the politics of education, 2nd edn. London: Routledge.

Greer, J.M. (2011) The Onset of Catabolic Collapse, Energy Bulletin, 19 January. http:/ / bit.ly/fm2nEL

Hall, R. (2009) Towards a Resilient Curriculum for HE, DMU Learning Exchanges, 8 December. http: / bit.ly/9Nxdvs

Hall, R. (2010) The iPad and the Essentialism of Technology in Education, DMU Learning Exchanges, 8 September. http: / / bit.ly/aMMrqG 
Hall, R. \& Hall, M. (2010) Scoping the Pedagogic Relationship between Self-Efficacy and Web 2.0 Technologies, Learning, Media and Technology, 35(3), 255-273. http: / / dx.doi.org/10.1080/17439884.2010.485204

Harvey, D. (2010) The Enigma of Capital: and the crises of capitalism. London: Profile Books.

Helm, D., Smale, R. \& Phillips, J. (2007) Too Good to Be True? The UK’s Climate Change Record, 10 December. http:/ / bit.ly/efQfC7

Hemmi, A., Bayne, S. \& Land, R. (2009) The Appropriation and Repurposing of Social Technologies in Higher Education, Journal of Computer Assisted Learning, 25(1), 19-30. http: / / dx.doi.org/10.1111/j.1365-2729.2008.00306.x

Herring, H. \& Roy, R. (2002) Sustainable Services, Electronic Education and the Rebound Effect, Environmental Impact Assessment Review, 22(5), 525-542. http: / dx.doi.org/10.1016/S0195-9255(02)00026-4

Higher Education Academy \& Joint Information Systems Committee (2010) Open Educational Resources Programme - Phase 2. http: / bit.ly/149LfB

Higher Education Funding Council for England (2011) HEFCE Strategy Statement: Opportunity, Choice and Excellence in Higher Education. http: / / bit.ly/g2FZnP

Hirsch, R.L. (2008) Mitigation of Maximum World Oil Production: shortage scenarios, Energy Policy, 36(2), 881-889. http: / dx.doi.org/10.1016/j.enpol.2007.11.009

Hirsch, R.L., Bezdek, R. \& Wendling, R. (2005) Peaking of World Oil Production: impacts, mitigation and risk management, February. http: / / 1.usa.gov/OsexK

Holloway, J. (2002) Change the World without Taking Power. London: Pluto Press.

Hopkins, R. (2009) Resilience Thinking: an article for the latest 'Resurgence', Transition Culture, 21 October. http:/ / bit.ly/3ugobl

Hubbert, M.K. (1956) Nuclear Energy and the Fossil Fuels. Publication No. 95, Shell Development Company, Houston, June. http:/ / bit.ly/ cfjlxz

IBM (2010) Energy and Low Carbon: more haste, less waste. http:/ /ibm.co/eJOxaR

International Energy Agency (IEA) (2010a) World Energy Outlook 2010: executive summary. Paris: IEA. http:/ / bit.ly/cGz449

International Energy Agency (2010b) World Energy Outlook 2010: key graphs. http:// bit.ly/boyZYI

International Energy Agency (2011) Oil Market Report. http:/ / bit.ly/eb8ha

Jackson, T. (2007) Rebound Launch. Keynote presentation at Energy Institute, London, 31 October. http: / bit.ly/cldoaZ

Jackson, T. (2009) Prosperity without Growth? The Transition to a Sustainable Economy. London: Sustainable Development Commission. http:/ / bit.ly/xLKGf

Johnson, L., Smith, R., Willis, H., Levine, A. \& Haywood, K. (2011) The 2011 Horizon Report. Austin, TX: New Media Consortium. http:/ / bit.ly/fYalBu

Joint Information Systems Committee (2011) Greening ICT Programme. http:/ / bit.ly/cWi47q

Jones, P., Selby, D. \& Sterling, S. (2010) Sustainability Education: perspectives and practice across higher education. London: Earthscan.

Kilian, L. (2009) Oil Price Volatility: origins and effects. http:/ / bit.ly/e0t5Og

Lamb, B. (2010) Open Contempt. Closing keynote address at UK Joint Information Systems Committee Open Educational Resources International Symposium, London, 23 July. http: / / bit.ly/99TI2h

Levitt, B.B. \& Glendinning, C. (2011) The Problems with Smart Grids, Energy Bulletin, 18 March. http: / / bit.ly/dWtQjq

Meiksins-Wood, E. (1997) Back to Marx, Monthly Review, 49(2). http: / bit.ly/gJIsK4

Mohrman, N. (2011) Educational Exchanges: what China should not adopt from United States higher education, CERC Studies in Comparative Education, 27(2), 127-144.

Neary, M. \& Hagyard, A. (2010) Pedagogy of Excess: an alternative political economy of student life, in M. Molesworth, L. Nixon \& R. Scullion (Eds) The Marketisation of Higher Education: the student as consumer. London: Routledge.

Neary, M. \& Winn, J. (2009) Student as Producer: reinventing the undergraduate curriculum, in M. Neary, H. Stevenson \& L. Bell (Eds) The Future of Higher Education: policy, pedagogy and the student experience, pp. 192-210. London: Continuum.

New Economics Foundation (NEF) (2009) The Great Transition: a tale of how it turned out right. London: NEF. http: / / bit.ly/8oJfeg 
Noble, D.F. (1984) Forces of Production: a social history of industrial automation. New York: Alfred A. Knopf.

Noble, D.F. (1998) Digital Diploma Mills: the automation of higher education, First Monday, 3(1). http:/ / bit.ly/cU1ml9

Oil Depletion Analysis Centre (ODAC) \& Post Carbon Institute (PCI) (2010) Preparing for Peak Oil: local authorities and the energy crisis. London: ODAC \& PCI. http:/ / bit.ly/dLxnCJ

Owen, N.A., Inderwildi, O.R. \& King, D.A. (2010) The Status of Conventional World Oil Reserves: hype or cause for concern? Energy Policy, 38(8), 4743-4749. http:/ / dx.doi.org/10.1016/j.enpol.2010.02.026

Payton, S. \& Williamson, B. (2009) Enquiring Minds: innovative approaches to curriculum reform. Year 4 Report, October. Bristol: Futurelab. http:/ / bit.ly/3MtrM2

Peer to Peer University (2010) About P2PU. http: / p2pu.org/

Pielke, Jr., R. (2009) The British Climate Change Act: a critical evaluation and proposed alternative approach, Environmental Research Letters, 4(2), 1-7.

Pielke, Jr., R. (2010) The Climate Fix: what scientists and politicians won't tell you about global warming. Lyndhurst, NJ: Barnes \& Noble.

Raffle, A.E. (2010) Oil, Health and Healthcare, British Medical Journal, 341, c4596. http:/ / dx.doi.org/10.1136/bmj.c4596

Ravenscroft, A. (2009) Social Software, Web 2.0 and Learning: status and implications of an evolving paradigm, Journal of Computer Assisted Learning, 25(1), 1-5. http: / / dx.doi.org/10.1111/j.1365-2729.2008.00308.x

Really Open University (2011) Really Open University. http:/ / bit.ly/bS0tl8

Royal Academy of Engineering (RAE) (2010) Generating the Future: UK energy systems fit for 2050. London: RAE. http: / / bit.ly / hnMVm8

Selwyn, N. (2010) Looking beyond Learning: notes towards the critical study of educational technology, Journal of Computer Assisted Learning, 26(1), 65-73. http: / / dx.doi.org/10.1111/j.1365-2729.2009.00338.x

Shepherd, J. (2010) University Teaching Budgets Slashed, Guardian, 1 February. http:/ / bit.ly/ cmpzpJ

Sorrell, S. (2007) The Rebound Effect: an assessment of the evidence for economy-wide energy savings from improved energy efficiency. London: UK Energy Research Centre. http: / bit.ly/aKAro6

Thrift, N. (2010) A Question (about Universities, Global Challenges, and an Organizational-Ethical Dilemma), GlobalHigherEd, 8 April. http://bit.ly/b8uGpz

UK Industry Taskforce on Peak Oil and Energy Security (2010) The Oil Crunch: a wake-up call for the UK economy. London: Ove Arup. http://bit.ly/cAcmrL

United Nations (2010) The Human Development Index (HDI). http:/ / bit.ly/9GoWte

University of Reading (2010) This Is Me Project. http:/ / thisisme.reading.ac.uk/

US Energy Information Administration (2011) This Week in Petroleum. http:/ / .usa.gov/haVz4K

Ward, I., Ogbonna, A. \& Altan, H. (2008) Sector Review of UK Higher Education Energy Consumption, Energy Policy, 36(8), 2939-2949. http:/ / dx.doi.org/10.1016/j.enpol.2008.03.031

Willetts, D. (2011) Speech at Universities UK Spring Conference, Woburn House, London, 25 February. http:/ / bit.ly/g41CtU

Williams, R. (1961) The Long Revolution. London: Chatto \& Windus.

Winn, J. (2010) Posts Tagged 'ResilientEducation', Expedient Means, University of Lincoln. http:/ / bit.ly/9sexuE

World Bank (2010) Energy Use (kg of Oil Equivalent Per Capita). http:/ / bit.ly/eCfueF

World Bank (2011) World Bank Indicators. http:/ / bit.ly/9B9XqR

Zittel, W. (2001) Analysis of the UK Oil Production, 22 February. http:/ / bit.ly/aPuDks

RICHARD HALL is the Head of Enhancing Learning through Technology at De Montfort University, Leicester, United Kingdom. He is also a National Teaching Fellow and a Reader in Education and Technology. He is responsible for the academic implementation of technologyenhanced learning with the aim of enhancing the student experience. Richard has worked on several research projects in the United Kingdom that have investigated: mainstreaming Web 2.0 technologies across the university; the relationship between transitions into higher education and 
independent learning; green information and communication technologies; and the use of technologies to support students studying remotely. Correspondence: Dr Richard Hall, Head of Enhancing Learning through Technology, Directorate of Library and Learning Services, De Montfort University, Leicester LE1 9BH, United Kingdom (rhall1@dmu.ac.uk).

JOSS WINN is a Senior Lecturer working in the Centre for Educational Research and Development at the University of Lincoln, United Kingdom, where he undertakes research and development in the use of technology in higher education. Correspondence: Joss Winn, Technology Officer, Centre for Educational Research and Development, University of Lincoln, Brayford Pool, Lincoln LN6 7TS, United Kingdom (jwinn@lincoln.ac.uk). 